\title{
A Governance Perspective on Net Zero Energy Building Niche Development in India: The Case of New Delhi
}

\author{
Mansi Jain ${ }^{1}$, Thomas Hoppe ${ }^{2, *}$ (D) and Hans Bressers ${ }^{1}$ \\ 1 Department of Technology and Governance for Sustainability (CSTM), Institute for Innovation and \\ Governance Studies (IGS), Faculty of Behavioral, Management and Social Studies (BMS), \\ University of Twente, P.O. Box 217, 7500 AE Enschede, The Netherlands; m.jain-1@utwente.nl (M.J.); \\ j.t.a.bressers@utwente.nl (H.B.) \\ 2 Policy, Organisation, Law and Gaming (POLG), Department of Multi-Actor Systems (MAS), \\ Faculty of Technology, Policy and Management (TPM), Delft University of Technology, Jaffalaan 5, \\ 2628 BX Delft, The Netherlands \\ * Correspondence: T.Hoppe@tudelft.nl; Tel.: +31-15-278-2783
}

Received: 30 June 2017; Accepted: 28 July 2017; Published: 3 August 2017

\begin{abstract}
The net zero-energy building (NZEB) concept has recently gained prominence worldwide. Large scale adoption and implementation of NZEBs would potentially contribute greatly to greening of the building sector. However, it is still at a nascent stage of niche formation. This paper aims to assess the governance context for adoption and uptake of NZEBs through niche formation in India by addressing the research question: What is the state of governance in New Delhi regarding NZEB niche development? A case study research design is used to answer this question. The Governance Assessment Tool (GAT) and Strategic Niche Management (SNM) are used to analyze the New Delhi case. Data collection involved in-depth interviews with fourteen key stakeholders. Data were analyzed using the qualitative data analysis software (ATLAS.ti). The results reveal that the governance context is only marginally supportive towards NZEB niche formation due to qualities of moderate extent, flexibility and intensity. Actor network formation was identified as an important driver which influences other elements of governance, as well as factors stimulating strategic niche management.
\end{abstract}

Keywords: net zero energy buildings; energy transition; governance; niche formation; strategic niche management

\section{Introduction}

As global warming and fossil fuel depletion highlight the need to save energy, demand for energy in buildings is bound to increase [1]. Green buildings with the highest level of energy efficiency are now being projected as net zero energy buildings (NZEBs; See Appendix B for the entire list of Acronyms used in this article) with the use of renewable energy technology for energy production. This has recently gained a lot of attention from research communities, early adopters of construction innovations, policy makers as well as green building rating systems, such as Leadership in Energy and Environment Design-LEED, setting ambitious targets to transform the building sector by adopting low, near or net zero energy building concepts. This can be achieved by adopting solar passive building design strategies, the use of energy efficient technologies, and integration with renewable energy (RE) systems to fulfill the remaining energy demand through self-generation [2-4]. Such buildings offer a promising solution to deal with future energy challenges with limited environmental impact [5]. 
In India, however, energy efficient buildings and green buildings have seen an increased uptake in recent years, where the country secured the third position in the 2016 U.S. Green Building Council (USGBC) annual rankings of top 10 countries for LEED. India has 15.90 million gross square meters (GSM) of LEED-certified space and an additional 89.28 million cumulative GSM of LEED-certified and registered space [6]. India is also among the top 10 countries outside the United States making progress in sustainable building design, construction and operations. In the recently published 'Smart Market' report it is stated that by 2018, the green building industry in India is expected to increase by 20 per cent, driven largely by environmental regulations and demand for healthier neighborhoods [6]. Despite this, green building uptake also meets with several challenges such as lack of public awareness, lack of public incentives, high perceived upfront investment, and lack of market demand [6].

Although India's green building sector has gained momentum, numerically it can be considered rather small when compared to the number of buildings which are planned to be constructed in the country till 2030. When looking at the estimated 2030 building volume, $70 \%$ remains to be constructed [7]. In this view scaling up NZEBs among the new to be constructed volume of buildings can be viewed as a potential "game changer" by curbing GHG emissions and drastically reducing energy demand of the building sector in India.

Currently, in India the building sector is responsible for nearly $33 \%$ of the total energy consumption [8]. From this perspective, large scale development of NZEBs has the potential to deal with future energy challenges and ensure energy security for the country, which is especially urgent in urban settings [9]. However, this requires structural changes and innovations in policy, regulations, user practices, market incentives, awareness as well as new technology to overcome the existing barriers for green markets [10]. At the moment the market for NZEBs in India is at a nascent stage of niche formation, with only a handful of NZEB demonstration projects running. Results from previous research revealed that the NZEB niche is immature and growing only slowly [11]. Currently, there is no single nationally accepted definition of NZEB in India as the concept is still considered to be in its infancy. However, frontrunners define it as, "highly energy efficient building with extremely low energy demand, which is met by renewable energy sources". Such buildings produce as much energy as they consume (annually) [11].

Governance arrangements play an important role in stimulating innovation and supporting diffusion and adoption of new sustainable technologies (in our case NZEB technology), for example by introducing innovation policies and a conducive framework for implementation of such policies [12]. This also applies to innovation systems, for instance incentives, networks, structure, and culture that have to do with the introduction and innovation diffusion of NZEBs in the building sector in India [13]. In this perspective, this paper aims to analyze the state of governance in a selected region in India, in this case New Delhi, to assess how supportive or obstructive the governance context is vis-à-vis niche formation of NZEBs. The main research question is: What is the state of governance in New Delhi regarding NZEB niche development?

This paper is structured as follows: in Section 2, the theoretical frameworks of the Governance Assessment Tool (GAT) and Strategic Niche Management (SNM) are presented. In Section 3, the research design and methodology are presented. In Section 4, the results of the case study analysis are presented. In Section 5, the results of the analysis are discussed. And finally, in Section 6, the conclusions are presented.

\section{Theoretical Framework}

This section presents the two theoretical frameworks which will be of interest to understand the niche formation process of NZEBs from a governance perspective. Section 2.1 elaborates on governance and its influence on facilitating and stimulating innovation in a particular context. This leads to introducing the GAT and its conceptual background in the Contextual Interaction Theory (CIT). It provides a vision towards current and possible future pathways for the governance context regarding niche formation and diffusion-adoption of NZEBs. Secondly, SNM is briefly presented in Section 2.2. 
It explains the niche formation and diffusion of novel sustainable technologies through the formation of protected niches, and gradual breakdown of regime barriers. SNM and GAT will be compared to advance the understanding and the analytical approach of governance processes that have to do with niche development, and deepen understanding of governance of innovations in a given economic sector. Theoretically, the focus of this paper is to analyze sectoral energy transition and niche formation of sustainable energy innovations from a governance and policy perspective. In this sense, it contributes to a growing body of literature in this domain [14].

\subsection{Governance Assessment Tool}

The GAT was developed as an evaluative framework to assess the quality of governance in a specific context, specifically to evaluate a particular implementation setting (vis-à-vis certain issues, policy instruments or projects) in terms of supportive or restrictive for such implementation. The conceptual basis of the tool consists of a collection of insights on governance, and has a background in the CIT [15]. The CIT is a third generation implementation theory where implementation is not seen as a top-down process but as multi-actor interaction process influenced by the actors who are involved. According to the CIT, there are three core characteristics per actor: motivation, cognition and resources. The "motivations, that may spur the actors into action, their cognitions, information held to be true, and their resources, providing them with capacity to act individually and power in relation to other actors" [16] (p. 45). The governance model in the CIT consists of questions that attempt to determine: Where? Who? What? How and with What? [17]. These questions respond to characteristics that feature modern governance systems [17]. They are multi-level, multi-actor, multi-faceted, multi-instrumental and multi-source-based [18].

The governance concept as used by the GAT has its roots in public policy, public administration and governance literature, and can be viewed as an attempt to organize the multiplicity of aspects mentioned in those literatures into a concise fashion [19]. Governance refers to, "all processes of governing, whether undertaken by a government, market or network, whether over a family, tribe, formal or informal organization, or territory, and whether through laws, norms, power or language. Governance differs from government in that it focuses less on the state and its institutions, and more on social practice and activities" ([20], p. 1). Therefore, governance can be seen as "beyond (merely) government", and a context for decision-making and implementation; it can be both supportive and restrictive for those processes. The governance context here, assumes the existence of a multiplicity of actors, levels, goals, instruments and different means that can be applied [21]. As a context, governance, to some degree, restricts and to some degree enables actions and interactions in a certain part of society [19]. The GAT helps to assess and identify the strong and weak points in the governance context (in our case this would be vis-à-vis NZEB niche development). The tool predominantly draws attention to understanding of existing situations that can obstruct policies and projects under complex and dynamic conditions [22].

\subsubsection{The Dimensions of the Governance Assessment Tool}

The GAT framework introduces five dimensions that provide a clear overview of the governance context (or contents of a governance regime in a certain area with certain issues). The dimensions of the governance context that are central to the GAT concern:

1. Levels (which are not necessarily administrative levels): governance assumes the general multilevel character of policy implementation.

2. Actors and their networks: governance assumes the multi-actor character of policy implementation.

3. Perception of the problem and objectives (not just the objectives): governance assumes the multifaceted character of the problems and objectives of policy implementation.

4. Strategies and instruments: governance assumes the multi-instrumental character of policy strategies for policy implementation. 
5. Resources and organization of implementation: governance assumes the complex multi resource bases for implementation of policy [22].

There are four quality criteria in order to assess the aptness of the governance regime [16]. These four quality criteria include: extent, coherence, flexibility and intensity [23]. The five governance dimensions and four qualities together form the core of the GAT. The quality criteria assess to what extent the governance context is supportive or restrictive for the policy process.

By analyzing the five dimensions of governance according to the four qualities of the governance regime, one can attain a very pragmatic understanding of how different elements of governance interact and hence influence a particular implementation setting, in our case adoption of NZEBs. Extent is a quality of a governance regime that refers to how completely it considers the various elements that have an impact on the process at stake (in this case NZEB niche development). The coherence of that same regime relates to how the various elements of the regime strengthen each other (rather than weaken each other). Given that the actors are different and important in different settings within a particular governance context; effective implementation will also be influenced by the flexibility available. In a flexible governance regime, actors have formal and informal liberties and stimuli to act towards the implementation actions that assist in achieving goals. Finally, intensity is extent "to which the regime elements urge changes in the status quo or in current developments" [24]. These dimensions can be used to follow up the first descriptive step and enable a more in-depth picture of the governance setting regarding a given issue (see Table 1).

\subsection{Strategic Niche Management}

SNM [25-32] provides insight into fostering technological and social change and at the same time initiates sustainable innovations at the niche level. SNM is an analytical framework designed to facilitate and study the introduction and diffusion of new sustainable technologies through societal experiments that contribute to forming a niche [25].

SNM theorists argue that successful radical innovations derive from socio-technical experiments in which various stakeholders collaborate, exchange information, knowledge and experiences. Therefore, SNM involves participation of several actors making it a multi-actor approach [26]. It states that governments (as participating actors) can be instrumental in facilitating wider transitions. It also illustrates how widespread technology change within well-established socio-technical systems can be achieved $[28,31,32]$. This can be done by facilitating the process of niche formation and setting up a set of successive experiments, often supported by (government induced) policy instruments that support niche development processes (e.g., by subsidy schemes, regulatory exemptions, or programs that include pilot projects). Many SNM scholars explain the success or failure of niches by analyzing the interaction between the three main factors influencing niche processes, i.e., shaping of expectations, building of social networks, and learning processes $[25,26,33]$. SNM not only focuses on niche formation by organising experiments, but also by targeting the gradual breakdown of regime structures and barriers that block niche development [27].

\subsection{The Governance Assessment Tool and NZEB Niche Development}

This paper uses the GAT as the main analytical framework. Using the GAT provides insights on the current governance context of NZEB demonstration projects and NZEB niche development in regions that are studied. The assessment can highlight the challenges in the governance regime which might obstruct or slow down the large-scale implementation and adoption of NZEBs, but may also help to identify potential drivers and strengths. In addition, the results can be used to make a holistic ex- ante evaluation of how the governance context can influence collaborative management of the NZEB niche development process in a particular region. 
Table 1. Matrix of the Governance Assessment Tool (adapted from: [16,24]).

\begin{tabular}{|c|c|c|c|c|}
\hline Dimensions & Extent & Coherence & Flexibility & Intensity \\
\hline Levels and scales & $\begin{array}{l}\text { How many levels are } \\
\text { involved and dealing with } \\
\text { an issue? Are there any } \\
\text { important gaps or } \\
\text { missing levels? }\end{array}$ & $\begin{array}{l}\text { Do these levels work together and do } \\
\text { they trust each other between levels? To } \\
\text { what degree is the mutual dependence } \\
\text { among levels recognized? }\end{array}$ & $\begin{array}{l}\text { Is it possible to move up and down } \\
\text { levels (up scaling and down scaling) } \\
\text { given the issue at stake? }\end{array}$ & $\begin{array}{l}\text { Is there a strong impact from a } \\
\text { certain level towards behavioral } \\
\text { change or management reform? }\end{array}$ \\
\hline Actors and networks & $\begin{array}{l}\text { Are all relevant } \\
\text { stakeholders Involved? } \\
\text { Who is excluded? }\end{array}$ & $\begin{array}{l}\text { What is the strength of interactions } \\
\text { between stakeholders? In what ways are } \\
\text { these interactions institutionalized in } \\
\text { joint structures? What is the history of } \\
\text { working together? Is there a tradition } \\
\text { of cooperation? }\end{array}$ & $\begin{array}{l}\text { Is it possible that new actors are } \\
\text { included or even that the lead shifts } \\
\text { from one actor to another when there } \\
\text { are pragmatic reasons for this? Do the } \\
\text { actors share in 'social capital', allowing } \\
\text { them to support each other's tasks? }\end{array}$ & $\begin{array}{l}\text { Is there a strong pressure from } \\
\text { an actor or actor coalition } \\
\text { towards behavioral change or } \\
\text { Management reform? }\end{array}$ \\
\hline $\begin{array}{l}\text { Problem perspectives } \\
\text { and goal ambitions }\end{array}$ & $\begin{array}{l}\text { To what extent are the } \\
\text { various problem } \\
\text { perspectives taken care of? }\end{array}$ & $\begin{array}{l}\text { To what extent do the various goals } \\
\text { support each other or are they in } \\
\text { competition or conflict? }\end{array}$ & $\begin{array}{l}\text { Are there opportunities to } \\
\text { re-assess goals? }\end{array}$ & $\begin{array}{l}\text { How different are the goal } \\
\text { ambitions from the status quo } \\
\text { or business as usual? }\end{array}$ \\
\hline $\begin{array}{l}\text { Strategies and } \\
\text { instruments }\end{array}$ & $\begin{array}{l}\text { What types of } \\
\text { instruments are included } \\
\text { in the policy strategy? }\end{array}$ & $\begin{array}{l}\text { To what extent is the incentive system } \\
\text { based on synergy? Are trade-offs in cost } \\
\text { benefits and distributional effects } \\
\text { considered? Are there any over-laps or } \\
\text { conflicts of incentives created by the } \\
\text { included policy instruments? }\end{array}$ & $\begin{array}{l}\text { Are there opportunities to combine or } \\
\text { make use of different types of } \\
\text { instruments? Is there a choice? }\end{array}$ & $\begin{array}{l}\text { What is the implied behavioral } \\
\text { deviation from current practice } \\
\text { and how strongly do the } \\
\text { instruments require and } \\
\text { enforce this? }\end{array}$ \\
\hline $\begin{array}{l}\text { Responsibilities and } \\
\text { resources }\end{array}$ & $\begin{array}{l}\text { Are responsibilities clearly } \\
\text { assigned and sufficiently } \\
\text { facilitated with resources? }\end{array}$ & $\begin{array}{l}\text { To what extent do the assigned } \\
\text { responsibilities create competence } \\
\text { struggles or cooperation within or across } \\
\text { institutions? Are they considered } \\
\text { legitimate by the main stakeholders? }\end{array}$ & $\begin{array}{l}\text { To what extent is it possible to pool the } \\
\text { assigned responsibilities and resources } \\
\text { as long as accountability and } \\
\text { transparency are not compromised? }\end{array}$ & $\begin{array}{l}\text { Are the amount of allocated } \\
\text { resources sufficient to } \\
\text { implement the measures needed } \\
\text { for the intended change? }\end{array}$ \\
\hline
\end{tabular}


It will also be of theoretical interest to use GAT in a way that allows for assessing niche development of a given sustainable innovation. This is rather novel since GAT has not been used for this purpose previously (and certainly not in transition studies research) to assess the development and diffusion of sustainable innovations in the built environment, nor in the energy domain.

Conceptually, the GAT and SNM reflect commonalities and can be used collectively to broaden the scope and understanding of long term transitions, sectoral innovations, policy implementation and the state of governance in niche development processes. In both the assessment frameworks, actors and their networks are highlighted as an important determinant for innovations and for assessing the governance context. Therefore, it should be right to assume that evaluating actors and their interactions (at niche level as well as at sectoral level) could play a key role in understanding innovation and diffusion of sustainable technologies, and the state of governance in a holistic way. Similarly, problem perceptions and goals (of where the governance is headed) which is a key aspect of governance in the GAT, shows similarities to shaping of expectations (converging towards shared visions and goals). Although responsibilities and resources (from the GAT) and learning process (from the SNM) do not specifically reflect any conceptual commonalities, they may be interdependent on each other (e.g., efficient use of resources-human and capital resources-can directly affect the learning process and vice-versa) Moreover, in facilitating learning processes sequential experimentation is required. This requires the mobilization of resources by actors who desire further experimentation, foster learning processes, and i support niche formation.

The GAT complements conceptual elements of SNM and hence gives us the opportunity to assess complementarities of the governance setting through a "SNM lens". SNM on the other hand supports and complements GAT by understanding which policy and market barriers prevent innovation, which are largely termed as regime barriers. Moreover, it adds the niche-regime-landscape dimension to the (already multi-dimensional) governance assessment framework. Therefore, this paper will first use GAT to assess case study data, and then subsequently assess conceptual complementarities and differences when reflecting on empirical data from a SNM perspective.

\section{Research Design and Methodology}

A case study design was used to analyze the governance of NZEB niche formation in New Delhi. The latter, the capital of India, was selected as a single case study to illustrate how the GAT can be applied to NZEB niche formation, and address how it compares and contributes to more traditional SNM analysis.

\subsection{Case Selection}

Next to being an illustrative case, New Delhi is also important because of its extremely high number of inhabitants and the degree of urbanization (which includes a vast building sector). New Delhi also reflects a high level of institutional and governance complexities, next to exhibiting vast developments in the green building sector as compared to the other parts of the country. Therefore, within the Indian realm, we believe that the New Delhi case would be the best one to study NZEB niche development from a governance perspective. The highly-urbanized character of the region exerts a tremendous pressure on public delivery of services including housing, construction of new buildings, energy demand, and poses a great challenge for the city administration.

\subsection{The Building Sector in New Delhi}

New Delhi comprises of a total geographical area of 14,300 hectares (Figure 1) [34]. According to the Masterplan 2021, land use distribution in the capital area is nearly $45-55 \%$ under residential buildings, commercial space comprising of $3-4 \%, 4-5 \%$ for industrial, $15-20 \%$ of green space, $8-10 \%$ of public and semi-public facilities and circulation comprise of $10-12 \%$. Thus, nearly $60-70 \%$ of land use comprises buildings [34]. 


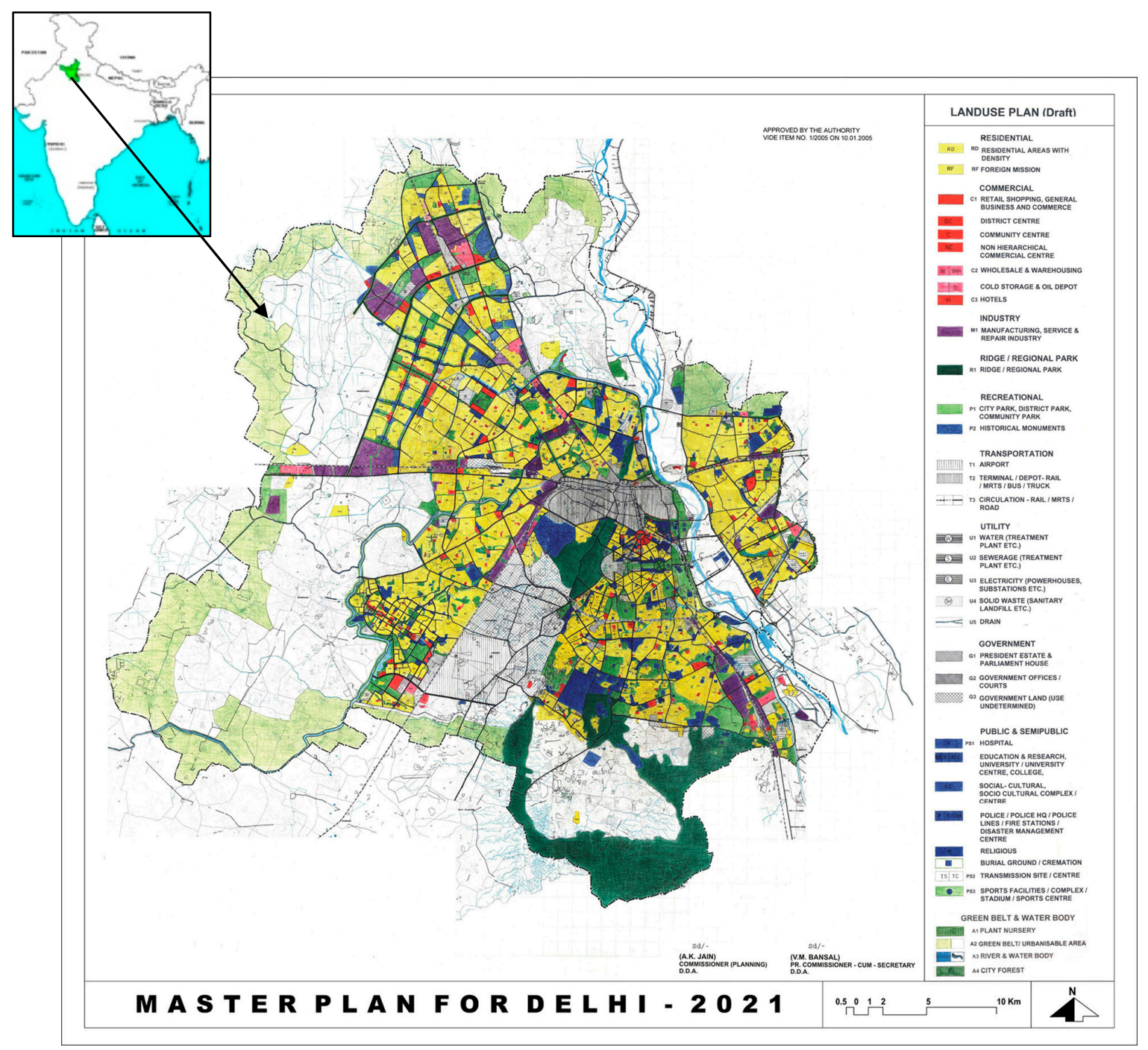

Figure 1. Masterplan of New Delhi, 2021 [34].

Buildings consume huge amounts of energy in lighting, cooling and ventilation [35]. New Delhi has the highest per capita power consumption among the States and Union Territories of India, with a consumption of $1265 \mathrm{KWh}$ per capita per annum as compared to the national average of $606 \mathrm{KWh}$ [7]. The power demand in New Delhi is vastly growing, at a rate of 5-6\% yearly [1], and the number of electricity consumers in the region has grown by $90.47 \%$ during the last ten years, with the highest growth in residential and commercial buildings [7].

As far as growth of energy efficient or green buildings is concerned, a vast uptake was observed for green certified buildings either under LEED, IGBC (the Indian Green Building Council certification system), and the Green Rating for Integrated Habitat Assessment (GRIHA; which is a rating tool that helps building owners to assesses the performance of their building against certain nationally acceptable benchmarks). LEED, IGBC and GRIHA constitute three independent green building rating systems that are used in India. In New Delhi, LEED certified buildings encompass 3.2 million sqft of built up space [36], LEED India (IGBC) comprises of 8.3 million sqft space [36] and GRIHA certified building comprise of 612,487 sqm of built up area [37].

The demand of energy conscious buildings has gained momentum mostly in the commercial building sector [38]. Several green certified buildings have also seen the uptake of renewable energy integration [39]. In GRIHA certified buildings, there is a mandatory criterion to offset $2.5 \%$ of annual 
energy load of the building by RE integration for daytime operated buildings, $0.5 \%$ by RE for full time operated buildings and no requirement for residential buildings [37]. Additional points are given in the criteria if the client exceeds the mandatory requirement. Therefore, these buildings can arguably be viewed as low energy or near zero energy buildings. However, as far as NZEBs are concerned, there is only one office building by the Ministry of Environment, Forest and Climate Change (MOEFCC), Indira Paryavaran Bhawan which claims to be India's first NZEB office building, which is also a GRIHA and LEED certified building [37]. In addition to RE integration criteria, GRIHA gives incentives to developers for GRIHA certification in new construction in New Delhi with $5 \%$ extra floor area ratio (FAR) in buildings [37]. This is seen a highly supportive.

Given these characteristics we view New Delhi as the region in India in which development and widespread uptake of NZEBs would be most urgent. For this reason, we consider it the most appropriate case in India (although it is somewhat of an extreme case) to assess its governance setting vis-à-vis NZEB niche development.

\subsection{Data Collection}

Data collection involved both primary and secondary data sources. First, a stakeholder analysis was conducted to identify important and relevant stakeholders who are part of the governance setting, and directly or indirectly affect the NZEB niche development process in the building sector. This also included actors who have a significant role in promoting green building, energy efficiency and nearor net zero energy buildings. This involved experts from national ministerial authorities, state and city authorities (municipal bodies, development authorities), building sector associations, financial institutions, building owners, construction developers, utility providers, architects, sustainability consultants, research and academia, manufacturers, and technology suppliers. These identified stakeholders were then shortlisted according to their direct engagement in actual green building projects, sustainable building projects, or NZEB projects in New Delhi.

For all of the identified stakeholders, an attempt was made to contact at least two to three actors from each stakeholder category (e.g., architects, academics, or developers). Contacts were made via e-mail, which were followed by phone calls. In some cases potential interviewees needed approval from their respective organizations. This especially applied to government agencies and international aid agencies. The first author (who participated in the USAID PACE-D TA Program which included NZEB promotion and awareness raising activities in one of the work packages) also used her professional network of expertise to get access to some of the selected organizations. After contact was made, each of the contacted experts was briefed about the research project, its aims and objectives. As a result, fourteen in-depth interviews with the stakeholders who agreed to participate were conducted between September 2015 and July 2016.

A semi-structured questionnaire was prepared for the interviews (see Appendix A). The questions were largely based on the five dimensions of the GAT framework along with the four complemented quality criterions as described in Section 2.1.1. In addition, questions containing key concepts from SNM were included. All the interviews were conducted face to face, recorded and transcribed into text files (interview transcripts), which were then used for analysis using the qualitative analysis software of ATLAS.ti. This software program assists qualitative researchers to locate, code, and annotate findings in text files, to weigh and evaluate their importance, and to visualize the complex relations, supporting data analysis (i.e., the interview transcripts) [40].

In addition to collecting data via face-to-face interviews, the main researcher (first author of this paper) participated in important project based meetings which included accelerating NZEB awareness and knowledge in the building industry. Finally, secondary sources of data were gathered and analyzed (e.g., published reports, newspaper articles, project briefs, etc.). 


\subsection{Data Analysis}

Data were treated using a coding scheme, consisting of codes resembling the five dimensions and the quality criteria of the GAT. This allowed for a systematic analysis. Each dimension of the GAT framework that is the five components formed the basis for developing codes in the transcribed documents against the four quality criteria's. A set of sub codes was further developed along with their occurrences. These were then used to weigh and evaluate their importance to assess the context with respect to the governance dimensions, and hence supported analysis of the data. The coding clusters supported in conducting an unbiased assessment of the data available from the interviews.

Furthermore, to avoid personal bias the interview transcripts and results of the analysis had to be approved by experts, having participated in the interviews. This happened-amongst others-during an expert meeting. In addition to this, the main researcher (first author) did not conduct the analysis alone, but also received feedback from the other researchers (supervisors) on the preliminary results of the analysis. Finally, personal bias was avoided by selecting interviewees via systematic sampling of the stakeholders by conducting a thorough stakeholder analysis before contacting the actors for interview participation. Hence, selection of interviewees was not restricted to 'snowballing' within author's expert network only.

Interviews and meetings with the representatives of all relevant stakeholders provided a clear picture of the governance context by allowing its assessment along the four governance criteria of extent, coherence, flexibility and intensity. The essence of those criteria was repeated each time before describing the observations made in the selected region.

\section{Results}

\subsection{Governance Assessment of the New Delhi Case Study}

\subsubsection{Extent: Are All Relevant Elements Taken into Account?}

Levels and scales: All government levels ranging from national, state to local level relevant to NZEB niche formation were found to be present, however no specific NZEB goals formulated by those governments were observed. There were separate goals from related energy efficiency (EE) and renewable energy (RE) policies. These related policies encompassed different levels of government; i.e., from national government to state level and to urban local bodies (for implementation).

At national level, the Bureau of Energy Efficiency (BEE, the statutory body under the Ministry of Power; Government of India (GoI)) facilitates and coordinates energy efficiency initiatives as per the Energy Conservation Act (EC Act, 2001). Second, the Ministry of New and Renewable Energy (MNRE) develops and facilitates large scale adoption of RE (renewable energy) technologies through integration in buildings by design and implementation of instruments. And third, building bye-laws are governed by the Ministry of Urban Development (MoUD). Thus, at the federal level there are three separate governmental bodies that deal with different aspects for potential NZEB adoption or for green buildings.

The regional or state level is the most prominent government agencies as far as implementation is concerned. They play an enforcing role to facilitate, and implement the policies. They exercise the power to amend policies to suit the regional and local climatic conditions and may, by rather legal and policy stipulations made by them, specify and notify the use of energy in the buildings. The Energy Efficiency and Renewable Energy Management Centre (EERMC), works as a State Designated Agency (SDA) to coordinate, regulate and enforce of the Energy Conservation Act of the region. It has also been designated as State Nodal Agency (SNA) for implementation of programs by the MNRE. The EERMC is responsible for promotion of renewable energy, energy efficiency and energy conservation in the New Delhi. For these reasons context (extent) is considered as supportive due to completeness of the levels required for NZEB adoption. 
Actors and networks: All relevant actors needed for NZEBs niche formation were present in the regional building sector in the region. However, only a handful of them were found to be actually involved, and appeared to be sufficiently motivated towards the concept of NZEB, largely due to the fact that NZEB is a relatively new expression for highly energy efficient green building with only very few running demonstration projects. Nevertheless, actors were found to be sufficiently involved with ongoing green buildings in the region. The actors that are motivated mostly concern energy efficiency experts, passive design architects, motivated clients (mostly public sector), technology manufacturers and suppliers (energy efficiency and on-site RE generation technology providers, advanced metering and building control technology providers). More relevant stakeholders-in particular government actors (in particular the EERMC) - "need to be actively involved to support the uptake and develop a mature NZEB niche, along with creating awareness", as stated by an architect during an interview.

There is sufficient potential to include architects, educational institutions, the research community, contractors, builders and developers, the industry association, and green building councils to make them aware about the NZEB concept.

In sum, all the actors that are necessary for decision making are basically present, but since the concept of NZEB is so new and under-researched in the Indian context many potential relevant actors are poorly motivated, and hardly involved. The present extent of actors is therefore considered 'neutral', but shows signs of progress.

Problem perceptions and goals: Actors have various perceptions, which were highlighted during the interviews. They include: poor and inadequate energy infrastructure along with inadequacy to deal with rising energy demand in buildings. It was also highlighted by 8 out of 14 interviewees that having only a few NZEB pilot demonstration projects is considered insufficient to raise the expectations (as they exhibit the potential, but do not drive the market). Economic benefits also need to be re-assessed as NZEBs are perceived as costly due to the use of expensive technologies (both related to energy efficiency and renewable energy). Interviewees also highlighted that green buildings still face resistance from mainstream developers and builders as they are largely concerned about increase in construction cost without resulting in higher selling price. Hence, developers and builders disregard anything that brings increased upfront costs. They are however, incentivized by giving extra FAR to GRIHA rated buildings in New Delhi. However, interviewees stated that developers are hardly attracted to this incentive in the region with very few applications for extra FAR.

In addition, various definitions describe NZEBs, and this varies across different contextual settings. In a dense urban setting like in New Delhi, interviewees argue that the NZEB needs to be re-assessed as per local and regional limitations, and needs. For example, due to high urban density, on-site NZEBs may not be a feasible option in the case of high rise buildings or potential of wind energy may be very limited. Nevertheless, various problem perspectives were found to be taken into consideration by different actors who were interviewed, which can therefore be seen as supportive in considering multiple aspects (e.g., technical, policy, economic aspects). However, the absence of goals for NZEB appears to restrict the adoption by many actors. Hence, when assessing the extent of problem definitions and goals it appears as to be rather neutral.

Strategies and instruments: Increased energy efficiency was seen as a high priority in the 12th five-year plan with various non-price incentives to promote energy efficiency. Several of these are included in the National Mission on Enhanced Energy Efficiency (NMEEE) (which was launched in 2008 as one of the eight missions in the National Action Plan for Climate Change). Energy efficiency in buildings is seen as one of the important five approaches adopted with a national Energy Conservation Building Code (ECBC; ECBC sets minimum energy standards for commercial buildings having a connected load of $100 \mathrm{~kW}$ or contract demand of $120 \mathrm{KVA}$ and above. While the Central Government has powers under the EC Act 2001, the state governments have the flexibility to modify the code to suit local or regional needs and notify them. Presently, the code is in voluntary phase of implementation. About 22 states are at various stages of mandating ECBC). Stakeholders consider this as highly supportive. 
There is continued attention to renewable energy resources in the 12th five-year plan, with national solar mission program initiated by the Government under NAPCC. The document emphasizes development of grid connected solar applications by offering feed-in-tariffs, net metering policy and other supportive policy instruments. The mission has set a target of 1,000 MW by 2017 reaching 1 million households in the country [41].

An addendum to the National Building Code of India (NBC) 2005 was finalized in 2016, including a chapter on sustainable building design, namely, 'Approach to Sustainability', so that sustainable construction practices are adopted in all future building constructions (the NBC, a comprehensive building code, is a national instrument providing guidelines for regulating the building construction activities across the country. It serves as a model code for adoption by all agencies involved in building construction works, be they public works departments, other government construction departments, local bodies or private construction agencies).

Previously, the government has shown interest towards developing a long-term roadmap for NZEBs through bilateral project agreements with the United States. The Energy Conservation and Commercialization (ECO) was implemented in three phases in which the NZEB concept was introduced in ECO III (the ECO III project worked towards identification and development of a collaboration framework between the US DOE National Research Laboratories, U.S. academic institutes and research centres, and the CEPT University in India (PACE-R)) phase (2006-12), and later again in the USAID PACE-D TA Program phase (2012-17), focusing on the extension of ECBC (towards super ECBC buildings) ready to integrate RE goals, and introducing the NZEB knowledge dissemination portal; a NZEB online knowledge dissemination portal has been launched by the Government under the USAID PACE-D TA program). These efforts were largely initiated by these agreements through international partnerships.

In sum, the presence of various programs and instruments toward EE and RE for buildings are seen as highly supportive. They reflect a high degree of extent in terms of separate instruments, and can potentially be combined into one holistic, integrated future NZEB policy (as voiced by nine out of 14 interviewees).

Responsibilities and resources: There is disparity and inconsistency between the large range of responsibilities which have been assigned to multiple actors especially between the national, state and local level. A large majority of interviewees consider it as imperative to demarcate a careful division of responsibilities between the state level government bodies, regional planning authorities and urban local bodies (ULBs). Moreover, there is the often-limited level of financial and knowledge resources, and for some of the stakeholders they are even decreasing. This also holds governmental parties that have to cope with the limited level of resource input when formulating innovative and cohesive policies. For this reason the building sector energy efficiency programs are often implemented through cooperation with international aid programs (e.g., the ECBC implementation with UNDP, EE high rise residential building guidelines with the Swiss Development Cooperation etc.). In sum, the extent of responsibilities and resources can therefore be viewed as rather limited.

\subsubsection{Coherence: Are the Elements Reinforcing Rather than Contradicting Each Other?}

Levels and scales: At the national level, the three national level agencies of BEE, MNRE and MoUD work within their respective jurisdictions and authorities. Their interactions are limited, which restricts opportunities to work together in an integrated manner. They appear to be isolated. This leads to institutional fragmentation and in turn to confusion at lower levels of government when the policies have to be implemented (and are depending on the compliance by municipalities, often using their own bylaws). They have separate goals and missions, and inter-ministerial coordination is absent. In addition, there is a lack of unified policy and national programs for NZEBs. This makes the context appear to be restrictive.

At the state level the institutional framework allows to work together for the implementation of EE and RE policies (with same SDA and SNA). This can be considered as positive and in support of 
NZEBs. Currently, the SDAs do not collaborate at the local level with ULBs to initiate enforcement of the policies for EE and RE in buildings. In doing so, they follow the top-down hierarchical institutional framework. In sum, coherence regarding levels and scales is considered as neutral.

Actors and networks: The strength of interaction between the existing actors was found to be fragile and is only possible through a formal platform, for example in the form of a conference or a workshop. In the past this has been possible through bilateral project agreements. These programs brought all the important stakeholders from the building industry and technology providers from India and the U.S. (and other Western countries such as the United Kingdom. and Switzerland) together. It helped to raise awareness and initiate discourse about the new and relatively unknown concept of NZEBs in the Indian building scenario by engaging in a series of workshops and exchange programs.

Similarly, awareness raising initiatives have been launched by the bilateral programs in the past to activate and engage relevant building industry actors to increase actor interactions and operationalise an industry alliance. However, the interviewees also revealed that the relatively active NZEB actors fail to interact or develop synergies with each other, and only end up interacting in formal arenas. They appear to be engaged in direct components of the on-going bilateral programs (e.g., in alliance formation, and demonstration projects of their own). As a result, they compete with each other for projects as they are part of the same industry. This relates to limitation in innovating on common interest between configurations of different NZEB pilot projects.

The set of active stakeholders can be viewed as a relatively closed group. They appear to operate in silos. As a result, there is a large gap in knowledge exchange between certain important stakeholders needed for innovation. Most of the stakeholders also refrain from sharing project data and exhibit a lack of trust towards others. Therefore, the coherence regarding actors and networks can be considered as poor.

Problem perceptions and goals: NZEB niche formation and its related problem perspectives are so far not reflected in the national government's policy goals. Currently, there is no shared goal, nor a single goal, nor a target for NZEBs in India (both at the national and the state level). Various goals have been formulated by the government on EE and RE in separate visions and programs. For example, the state government has announced an ambitious solar PV installation target for the year 2020 with a total installed capacity of 20,000 MW. A mandatory implementation of ECBC in the 12th five-year plan is expected to enable a greater shift in the building sector paradigm which sets minimum standards for energy performance in buildings. In addition, the government has set targets for reducing GHG emissions through the NAPCC which includes a mission for sustainable habitats. This encourages implementation of energy efficiency in buildings. In fact, the goals are there but to some extent they are enforced by different ministries and do not converge (as they are conceptualised in isolation). As a result, these goals are in conflict with each other and only add to fragmentation and complexity. Hence, coherence on problem perceptions and goals can be considered as limited.

Strategies and instruments: The related strategies and instruments that appear to support innovations in NZEBs are disconnected from each other both in both the policy making and implementation processes. They either focus on the EE or RE component of a NZEB, but hardly on both. Moreover, they (policies like ECBC codes or net metering) are often considered as restrictive due to their isolated character, and often exhibit a lack of coordination. On the other hand, they are neither really working against each other. Each of these instruments needs to become strong at the ground level for implementation for a comprehensive NZEB policy, with strengthening of local administrative bodies or municipalities. One of the interviewees highlighted the increased emphasis on RE components while neglecting the EE aspect of building design and construction. This may potentially impede future niche development for NZEBs. For these reasons coherence in terms of instruments and strategies can be considered as poor. 
Responsibilities and resources: No clear responsibility for NZEB niche formation was identified among stakeholders. This leads to institutes working in isolation from each other. In addition, there are many top-down hierarchical structures, which leads to a lack of transparency in terms of responsibilities and role division between stakeholders with regard to NZEBs. Most of the interviewees mentioned that these actors are given multiple responsibilities. Some of them are even overlapping, which in turn leads to duplicity of efforts, which happens almost at all levels of implementation. This also creates competence struggles and thereby avoidance of cooperation. A low degree of coherence is observed because these actors do not reinforce each other nor create synergies.

The existing responsibilities of the SDAs are not well supported by appropriate resources as they lack a substantially skilled labor force to understand and support NZEB adoption. Their resources are derived from sources that often have different goals. Since most of the actors have insufficient personnel and technological knowledge, they focus more on fulfilling their individual tasks than on recognizing and responding to the each other's needs.

In sum, coherence regarding responsibilities and resources can therefore be considered as limited.

\subsubsection{Flexibility: Are Multiple Roads to the Goals Permitted and Supported?}

Levels and scales: The institutional framework imposes decision making in governmental organizations in a top-down hierarchical manner. This also holds for responsibilities. These levels work within their own jurisdictional boundaries, and are restricted in this way. For instance, buildings with pre-set NZEB goals will also need additional approval at different stages of the project cycle. Hence, many organizations are involved at various levels. Moreover, ULBs, SDAs, and energy grid operators refrain from showing flexibility or convergence to other organizations. A fair degree of adaptiveness is only seen at the state level where states have the power and flexibility to modify the national government policies and programs to suit the local and regional needs, and address them. However, the other stakeholders involved in local implementation actions are stringent and do not encourage any change from their business as usual, in terms of practices and work procedures. For NZEB niche development this situation is viewed as restrictive with little opportunity for upscaling and downscaling policies between different government levels.

Actors and networks: Since the actor network is limited and hardly active, it is relatively easy for newcomers to enter. This also applies to entrance to readily established 'issue networks', which can therefore be considered 'flexible'. However, actors with experience and fair knowledge of NZEBs (the actors who have worked in NZEB pilots) may get a better say and authority in future projects. The flexibility regarding actors and networks is assessed as rather good.

Problems perceptions and goals: Since NZEBs are not yet part of (official) government policy, reassessment of goals is possible. Technical and economic aspects can be explored, as the NZEB concept is still immature. Therefore, case specific modifications are still possible, similar to those adopted in the Indira Paryavaran Bhawan project (a NZEB pilot project) in New Delhi, with a relaxation in a permissible built area and extension of roof projections to accommodate solar PV installations.

Few interviewees stated that NZEB definitions need reassessment specific to local context, which can be explored by frontrunners and public sector pilot projects. Re-alignment of goals is potentially possible. This is considered as supportive for future large-scale NZEB implementation. An optimized packaging of separate policies can be beneficial in the long run for the NZEB niche development and uptake thereafter. Therefore, the goals are seen as supportive for re-alignment. The flexibility of perspectives and goal ambitions is considered as relatively good. It should be considered that this degree of flexibility is partly a positive side effect of weak and fragmented government policies. Improvement on that side might endanger the observed flexibility, however.

Strategies and instruments: Existing instruments look flexible enough to be integrated with other existing policies and clusters. However, independent policies themselves are complex and have long process applications for implementation. For example, the net metering policy application process is 
considered as extremely lengthy, and is not considered user friendly. Even the process of approval takes a lot of time. Similarly, all of the NZEB stakeholders considered ECBC to be complex and difficult to understand (in particular by contractors and project developers). In spite of that, existing instruments can be applied in combination with each other. For example, ECBC compliant building owners can easily take incentives from MNRE for solar integration, and also for net metering application. In sum, the flexibility of strategies and instruments can be viewed as supportive to NZEB niche formation.

Responsibilities and resources: Since most of the NZEB concept is introduced to the Indian building sector by international bilateral programs, along with BEE, the responsibilities are not flexible and follow a bureaucratic approach of command and control. Moreover, there are only few opportunities to use resources for joint purposes. In addition, there is competition for the scarce resources available due to dependency on external resources. Therefore, flexibility regarding responsibilities and resources can be considered as limited.

4.1.4. Intensity: How Strongly Do the Elements Urge Changes in the Status Quo or in Current Developments?

Levels and scales: Most of the stakeholders consider central level regulatory measures as the strongest driving force for large scale implementation as well as innovation in the building sector. They view that the central government ministries should take an active role in developing a comprehensive set of unified NZEB policies and regulations. Currently, NZEBs are not present in the national government agendas nor missions, but only in a piecemeal fashion, and used by various authorities in diverging ways. Hence, there is neither an integrated approach, nor a program from the national government to support the uptake of NZEBs. In sum, the present intensity of levels and scales is considered neutral. However, according to our interviewees there is reason to believe that this may improve in the future.

Actors and networks: The existing actor network exerts only marginal pressure on any change from business as usual practices. A lack of support policies does not incentivize people to adopt NZEBs, but may (slightly) incentivize them towards taking an interest into energy efficient buildings (ECBC is a voluntary code) in New Delhi. This also applies to the Green Rating for Integrated Habitat Assessment (GRIHA) rating tool, which is basically targeted to all new public sector buildings (GRIHA attempts to minimize a building's resource consumption, waste generation, and overall ecological impact to within certain nationally acceptable limits/benchmarks). Moreover, most non-governmental stakeholders are looking for government initiatives to guide the actor network in the desired direction. However, currently this condition is absent. This limits the overall flexibility of actors and networks.

Problems perception and goals: Stakeholders observe that only few NZEB pilots show that the concept is feasible and RE integration is possible in buildings. Moreover, they do not show large scale societal and economic benefits. More so, performance of existing NZEB pilots is not shared with the public. This does not cause any shift in the existing building sector's regime. Awareness and interest among the industry is seen about energy efficiency buildings (through other market based green certifications, such as LEED and GRIHA certifications), but not particularly in relation to large scale adoption of NZEBs. However, present goals in the 12th five-year plan and at the state level to implement the ECBC code are considered to be in line with the market transition for energy efficient buildings. This is considered as rather positive. Government agencies can work towards a roadmap for large-scale NZEB uptake with large scale solar PV installation targets which have been recently initiated as the Delhi Solar policy. The goals that are accepted for the future at the state level are considered pretty ambitious, but will be confronted with a still existing strong emphasis on low initial building cost. The intensity for problem perceptions and goals can therefore be considered as neutral, as many economic goals are much stronger and without ample evidence that NZEB can actually be profitable this will exert "neutral" overall influence. 
Strategies and instruments: Due to ambitious national level targets on RE installation, the state SDA is implementing multiple solar specific instruments which mostly concern subsidies and other (financial) incentives. This, to some extent, increased the marketing value of the RE integration by raising more awareness and increasing knowledge levels about solar integration in buildings, with reduced costs. Hence, these instruments have been rather successful in changing expectations, and move the market towards more technology interventions in buildings. A neutral degree of intensity is observed regarding strategies and instruments. Regulatory measures and incentives with lucrative financial implications are also viewed as an important impetus to support actor network formation.

Responsibility and resources: Implementation is expected to occur according to the goals determined by higher levels of government, yet there is insufficient effort bestowed to ensure that the goals are actually met, and at minimal support for doing so. The existing intensity is weak as there is lack of financial resources, knowledge and skills for adoption and uptake of NZEBs in Delhi, with only one NZEB pilot project. It is only through the public sector NZEB pilot demonstrations that government agencies agree to the allocate additional budgets to cope with the high cost of NZEBs.

There is a perceived need to decrease the knowledge gap among the various actors in the building industry. In spite of the existing knowledge high upfront costs of these projects sometimes slows down the niche development process from private sector stakeholders. According to the interviewees, the state implementation agencies should get involved in increasing the stability of funding resources, recognizing and supporting innovative locally tuned implementation process through flexible and supportive instruments, and communication. The context on responsibility and resources is observed to be of restrictive nature.

\subsection{Overview}

A visual presentation of the governance of NZEB niche development in New Delhi is presented in Figure 2 (in the form of a 'GAT scorecard'). The green cells represent the results of the analyzed issues according to the issue matrix of the GAT in Table 1 that are considered satisfactory (positive); red cells, on the contrary, present results that are considered worrying (negative); and orange cells present results that are considered rather unsatisfactory or uncertain (neutral). The $(+)$ indicates that the present situation is changing in a positive direction or will change positively in the foreseeable future, whereas the (-) indicates that the situation is deteriorating, and is not likely to improve in the foreseeable future.

The governance context can be seen as highly incoherent, with fair degrees of flexibility, intensity, and extent (see also Figure 2). From the extent perspective, New Delhi can be seen to be in a position to adopt NZEBs, with a supportive context for actors and networks, problem perspectives and strategies and instruments. In this context, actors neither have incentives, nor are motivated by policies, because they are not in line with the goals. The local level actors have the authority, flexibility and support to address their own issues (within a given project boundary). Hence the incoherent but flexible and moderately intense context of the selected region shows that the governance context is in a position that allows actors to actively collaborate and manage NZEB niche development, provided that the supportive qualities are enhanced through collaborative management.

The case study revealed that government initiatives are largely taken through various strategies and instruments which partly support NZEB demonstration project implementation. In New Delhi, existing NZEB pilots are supported by the government by showcasing public buildings as NZEBs, with increased budgets.

What is initially interesting is the wide variety of configurations that have been observed. Given the interpretative nature of the GAT, the factors leading to these differences brought into the picture, through a further examination of the cases, could provide additional insights about the influencing factors and whether or not there are relationships between the various qualities related to them.

In addition, the results can be used to make a holistic evaluation of how the governance context influences collaborative management of NZEB niche development, and useful in comparing the 
existing strengths and weakness in the governance context. The GAT analysis revealed a few regime barriers such as isolated sectoral policies which are hardly coordinated nor integrated with other regime policies, which leads to sectoral policies restricting NZEB deployment in pilot projects (and up scaling at a later stage), in addition to minimal incentives to encourage contractors and project developers to pursue NZEB goals.

\begin{tabular}{|c|c|c|c|c|}
\hline \multirow[b]{2}{*}{ Dimension } & \multicolumn{4}{|c|}{ Criteria } \\
\hline & Extent & Coherence & Flexibility & Intensity \\
\hline Levels and scales & & & $(-)$ & $(+)$ \\
\hline Actors and networks & $(+)$ & & & \\
\hline $\begin{array}{l}\text { Problem perspectives and goal } \\
\text { ambitions }\end{array}$ & $(+)$ & $(-)$ & $(+)$ & $(+)$ \\
\hline Strategies and instruments & & & & \\
\hline \multirow[t]{2}{*}{ Responsibilities and resources } & & & & \\
\hline & \multicolumn{4}{|c|}{ Colors red: poor; orange: medium; green: good } \\
\hline
\end{tabular}

Figure 2. GAT results for the New Delhi NZEB case study.

While applying the SNM approach in assessing the governance setting in the selected case study, many insights can be drawn. As described in previous sections SNM uses problems and perceptions, social network formation and learning process as three important building blocks. The case study revealed that network formation was rather weak, as was shown in the GAT analysis by the lack of coherence. Network venues only comprised a few workshops and a conference. Moreover, most NZEB actors were found to operate in isolation. This, in turn, hampered learning processes, which eventually led to slow niche development. Project based goals and visions were found to influence project outcomes by allowing the stakeholders to work together on pre-set goals. However, a lack of knowledge, budget limitations, and a lack of resources proved serious challenges to the niche development process.

In line with SNM-which states that niches often receive government protection - the case study revealed that the only NZEB demonstration project in the region was protected by the government (through increased budget allocated for a public sector building project). In addition to this, the roof-top solar panels were granted roof extension beyond permissible by-laws making it as a special case for NZEB demonstration. Therefore, the pilot demonstration was highly protected by the government initiatives to showcase NZEB features. Hence, SNM highlights the protected space under which niches can grow. However, this was not observed in any other public building projects in the region. Other regime barriers also led to the slow growth of the niche (such as sectoral policies, which were found to be poorly aligned).

\section{Discussion}

From an SNM perspective, using the GAT to analyze the governance system for niche formation was useful in assessing the state of governance for fostering such innovations. SNM uses the three theoretical building blocks of problem perceptions and visioning, social network formation and learning process as primary niche formation processes with the important issue of creating 'protection' from the market to organize niche experiments [42]. This shows similarities to some of the GAT 
components, namely: actor and networks, perhaps somewhat to (adjusting) 'problems and goals', and (getting access to) resources (to afford new sets of experiments).

Moreover, applying the GAT as an analytical tool was useful to understand and assess the governance context in the building sector in the selected case study vis-à-vis NZEB niche development. The study is of theoretical interest as GAT allows for assessing the governance component of niche development and sustainable innovations (like NZEBs). This is rather novel since the GAT has not been used thus far to assess developments and diffusion of sustainable innovations in the built environment, nor in the energy domain. The challenge to use GAT in this way, however, urges one to rethink how to incorporate key theoretical notions of SNM with GAT.

In both the SNM and GAT assessment frameworks, actors and their networks are highlighted as overlapping drivers for innovations and for assessing the governance context in which innovations evolve. Therefore, evaluating and assessing actor (and actor-network) interactions forms a critical part of the GAT assessment framework. As social interaction processes in multi-actor arenas are mostly driven by the actors involved, these interactions form a central stage in the theoretical basis that is key to both GAT and SNM. Hence, interaction processes are considered as an ultimate driver for niche formation, sustainability transitions and innovation. In this sense, actor-networks can be seen as the key units of analysis in both the GAT and SNM frameworks, in particular because they form the key social configuration in which other important drivers for supportive governance context occur, such as problem perceptions and goals, levels and scales, strategies and instruments, and resources and responsibilities.

The theoretical components of SNM can be viewed as similar to some key elements of the GAT. Combining insights from the two concepts may allow for broadening the scope and furthering understanding of long term sustainable transitions, sectoral innovations, implementation of transition-oriented policies, and assessment of the role and state of 'governance' in niche development processes in sectoral systems. Furthermore, the four quality criteria mentioned in the GAT framework can be used to evaluate the niche development process with respect to the three building blocks of the SNM. For example, actor interactions, expectations, and learning processes can all be evaluated as per the four quality criteria's (extent, coherence, flexibility and intensity) to understand overlap with the GAT framework. This can be further elaborated in future empirical research. It will be interesting to augment understanding of the governance context of niche development and sustainable innovations (like NZEBs) through more empirical cases that are also analyzed using the GAT.

The findings also reveal the importance of international aid instruments to initiate sustainable innovation in the building sector for NZEBs, also influencing the governance context. For example, actor network formation was initiated largely by networking platforms under aid programs (e.g., via NZEB conferences and workshops), which in turn also influence policy instruments such as developing the ECBC code for buildings with component of super ECBC buildings ready for RE integration [11]. Hence, in developing countries, such as India, a large extent of building innovations is advocated and developed under those programs, thereby exerting a change of governance regime. The instruments used under those programs are seen as important drivers to bring about transition in sustainable technologies by kick starting the niche formation process [11,43].

\section{Conclusions}

In this paper the state of governance towards NZEB niche development was analyzed in case of New Delhi. A case study research design was used to assess the governance context It was found to be moderate in terms of extent, but rather incoherent, only moderately flexible, and intense in other areas. This shows that the governance context can be viewed as moderately supportive towards NZEB niche development on the one hand, but also restrictive on the other hand. The main results of the governance analysis are presented below:

- The study revealed that all of the levels relevant for NZEB adoption were present, but they were found to be isolated in relation to NZEB niche development. However, the presence of all the 
institutional levels is considered as positive in relation to the development of future innovation and diffusion programs.

- Similarly, most of the relevant actors needed for NZEB niche development were found to be present, but they were only poorly motivated towards building up the alliance network and to initiate knowledge building and learning.

- An increasing number of critical aspects for NZEB adoption are taken into account by the existing NZEB stakeholders, which provides a good test bed for creating visions and goals for the future uptake of the concept.

- Currently, most of the instruments and strategies are also present both related to energy efficiency and renewable energy integration in buildings, but they are not part of a holistic program (such as one unified NZEB policy or a code for implementation).

- The responsibilities and resources are seen as a weaker component of the governance context for NZEBs, as the resources are limited both in terms of capital investment and knowledge capacity.

Using the GAT in our opinion was useful and brought many aspects to light regarding the quality of the governance of NZEB niche development. The assessment highlighted the challenges in the regime which is obstructing and slowing down the introduction and diffusion of NZEB innovations, and at the same time identifying potential drivers to spur NZEB niche development. In addition, the results can be used to make a holistic ex-ante evaluation of how the governance context can influence collaborative management of the NZEB niche development process.

By using the GAT complementary to SNM, further understanding of the quality of governance in a given context was gained with additional insight into existing institutional levels, strategies and instruments, and the resources and responsibilities available. Having had a good experience in analyzing NZEB niche development while using both approaches, we suggest that the use of both can be recommended in future niche development studies, particularly those focusing on the governance of niche development. Therefore, the GAT as a qualitative assessment framework towards the state of governance which can be complemented with the mainstream SNM approach can potentially be used for informed decision making by the government and policy makers towards introduction and diffusion of new sustainable technologies in a developing country. Before doing so, we do, however, suggest researchers to pay attention to the presence of a few pre-existing conditions. These conditions concern:

(i) there needs to be some innovation in at least a certain (developed) phase of niche formation;

(ii) there needs to be at least some form of 'governance' (hence, not only market actor involvement, and coordination via the price mechanism, but also public and civic involvement, and at least some form of government intervention to support niche formation);

(iii) the siting of the case study needs to be in a developing country (i.e., not in a Western country).

Finally, we want to address limitations that should be kept in mind when reflecting on the results of this study. It mostly entails the fact that the selected case study is located in India, against the background of a developing country. This arguably contributed to focusing on a sectoral niche that was still immature or under-developed. In future research we suggest the GAT also to be used in empirical research comprising case studies of niches that are more developed, i.e., in further stages of niche development (e.g., early niche development, late niche development, diffusion and upscaling processes). Analyzing and comparing cases in different development stages would allow researchers to learn more about mechanisms that influence sectoral niche development in a specific region with a dynamic governance process. This would probably entail to (also) select cases of sectoral niche formation in developed countries. Moreover, an attempt could be made to compare the governance contexts of two regions within the country with separate state jurisdictions; this can be explored in future research. 
Acknowledgments: The authors would like to express their gratitude to the interviewees who graciously permitted the first author to interview them for the study reported in this paper.

Author Contributions: Mansi Jain, Thomas Hoppe and Hans Bressers conceived and designed the study. Mansi Jain collected data. Mansi Jain and Thomas Hoppe analyzed data. Mansi Jain, Thomas Hoppe and Hans Bressers contributed to the data analysis. Mansi Jain and Thomas Hoppe wrote the paper.

Conflicts of Interest: The authors declare no conflict of interest.

\section{Appendix A. Questionnaire}

\begin{tabular}{ll}
\hline Governance Dimension & Quality of the Governance Regime \\
\hline & Extent: How many administrative levels are involved and dealing with NZEBs? \\
& Are there any important gaps or missing levels? \\
Coherence: Do these govt. bodies work together and do they trust each? To what \\
degree is the mutual dependence among levels recognised? \\
Flexibility: Is it possible to move up and down levels (up scaling and downscaling) \\
given the issue at stake? \\
Intensity: Is there a strong impact from a certain government level on NZEB niche \\
development (e.g., on learning, networking, more pilot projects, scaling up of \\
NZEB best practices.
\end{tabular}

Extent: Are all relevant stakeholders involved? Are there any stakeholders not involved or even excluded?

Coherence: What is the strength of interactions between stakeholders? In what ways are these interactions institutionalised in stable structures? Do the stakeholders have experience in working together? Do they trust and respect

Actors and networks each other?

Flexibility: Is it possible that new actors are included or even that the lead shifts from one actor to another when there are pragmatic reasons for this? Do the actors share in 'social capital' allowing them to support each other's tasks?

Intensity: Is there a strong pressure from an actor or actor coalition towards stimulation of NZEB niche development

Extent: To what extent are various problem perspectives taken into account? Coherence: To what extent do the various perspectives and goals support each other, or are they in competition or conflict?

Problem perspectives and goal ambitions

Flexibility: Are there opportunities to re-assess goals? Can multiple goals be optimized in package deals?

Intensity: How different are the goal ambitions from the status quo or business as usual?

Extent: What types of instruments are included in the policy strategy? Are there any excluded types? Are monitoring and enforcement instruments included? Coherence: To what extent is the incentive system based on synergy?

Are trade-offs in cost benefits and distributional effects considered? Are there any Strategies and instruments overlaps or conflicts of incentives created by the included policy instruments? Flexibility: Are there opportunities to combine or make use of different types of instruments? Is there a choice?

Intensity: What is the implied behavioural deviation from current practice and how strongly do the instruments require and enforce this?

Extent: Are all responsibilities clearly assigned and facilitated with resources? Coherence: To what extent do the assigned responsibilities create competence struggles or cooperation within or across institutions? Are they considered legitimate by the main stakeholders?

Responsibility-ties and resources ( implementation)
Flexibility: To what extent is it possible to pool the assigned responsibilities and resources as long as accountability and transparency are not compromised? Intensity: Is the amount of allocated resources sufficient to implement the measures needed for the intended change? 


\section{Appendix B. List of Acronyms}

$\begin{array}{ll}\text { BEE } & \text { Bureau of Energy Efficiency } \\ \text { CIT } & \text { Contextual Interaction Theory } \\ \text { ECBC } & \text { Energy Conservation Building Code } \\ \text { EC Act } & \text { Energy Conservation Act } \\ \text { ECO } & \text { Energy Conservation and Commercialization } \\ \text { EE } & \text { Energy Efficiency } \\ \text { EEREMC } & \text { Energy Efficiency and Renewable Energy Management Centre } \\ \text { FAR } & \text { Floor Area Ratio } \\ \text { GAT } & \text { Governance Assessment Tool } \\ \text { GHG } & \text { Greenhouse gas } \\ \text { GRIHA } & \text { Green Rating for Integrated Habitat Assessment } \\ \text { GSM } & \text { Gross Square Meters } \\ \text { IGBC } & \text { Indian Green Building Council } \\ \text { LEED } & \text { Leadership in Energy and Environment Design } \\ \text { MOEFCC } & \text { Ministry of Environment, Forest and Climate Change } \\ \text { MNRE } & \text { Ministry of New and Renewable Energy } \\ \text { MoUD } & \text { Ministry of Urban Development } \\ \text { NAPCC } & \text { National Action Plan on Climate Change } \\ \text { NBC } & \text { National Building Code } \\ \text { NMEEE } & \text { National Mission on Enhanced Energy Efficiency } \\ \text { NZEB } & \text { Net Zero Energy Buildings } \\ \text { PACE-D TA } & \text { Partnership to Advance Clean Energy(-)Technical Assistance } \\ \text { RE } & \text { Renewable Energy } \\ \text { SDA } & \text { State Designated Agency } \\ \text { SDC } & \text { Swizz Development Corporation } \\ \text { SNA } & \text { State Nodal Agency } \\ \text { SNM } & \text { Strategic Niche Management } \\ \text { UNDP } & \text { United Nations Development Program } \\ \text { ULB } & \text { Unites States Green Building Council } \\ \text { USAID } & \\ \text { USGBC } & \end{array}$

\section{References}

1. IEA, International Energy Agency and WEO. World Energy Outlook 2013-Executive Summary. Available online: http:/ / www.iea.org/publications/freepublications/publication/WEO2013_Executive_Summary_ English.pdf (accessed on 10 June 2017).

2. Marszal, A.J.; Heiselberg, P. A Literature Review of Zero Energy Buildings (ZEB) Definitions; Department of Civil Engineering, Aalborg University: Aalborg, Denmark, 2009.

3. Voss, K.; Musall, E. Net Zero Energy Buildings-International Projects on Carbon Neutrality in Buildings; Walter de Gruyter: Munich, Germany, 2011; ISBN 978-3-0346-0780-3.

4. Salom, J.; Widén, J.; Candanedo, J.; Sartori, I.; Voss, K.; Marszal, A. Understanding Net Zero Energy Buildings: Evaluation of load matching and grid interaction indicators. In Proceedings of the Building Simulation, Sydney, Australia, 14-16 November 2011.

5. Gilijamse, W. Zero-energy houses in the Netherlands. In Proceedings of the Building Simulation, Madison, WI, USA, 14-16 August 1995; pp. 276-283.

6. Analytics, Godg Data. World Green Building Trends 2016 Smart Market Report. Available online: http:/ / www.czgbc.org/Download/World\%20Green\%20Building\%20Trends\%202016\%20SmartMarket $\%$ 20Report\%20FINAL.pdf (accessed on 10 June 2017).

7. The Energy and Resources Institute (TERI). Green Growth and Buildings Sector in India; The Energy and Resources Institute: New Delhi, India, 2015.

8. Natural Resources Defense Council (NRDC). Constructing Change: Accelerating Energy Efficiency in India's Construction Market; NRDC Council: New Delhi, India, 2012. 
9. Iqbal, M.T. A feasibility study of a zero energy home in Newfoundland. Renew. Energy 2004, 29, $277-289$. [CrossRef]

10. Buildings Performance Institute Europe (BPIE). Principles for Nearly Zero Energy Buildings; BPIE: Brussels, Belgium, 2011.

11. Jain, M.; Hoppe, T.; Hans, B. Analyzing sectoral niche formation: The case of net-zeroenergy buildings in India. Environ. Innov. Soc. Transit. 2016. [CrossRef]

12. Edquist, C. Systems of Innovation, Perspectives and Challenges; Oxford University Press: Oxford, UK, 2005; pp. 181-208.

13. Beerepoot, M.; Beerepoot, N. Government regulation as an impetus for innovation: Evidence from energy perfromance regulation in the Dutch residential builidng sector. Energy Policy 2007, 35, 4812-4825. [CrossRef]

14. Hoppe, T.; Van den Berg, M.M.; Coenen, F. Illustrating the use of concepts from the discipline of policy studies in energy research: An explorative literature review. Energy Res. Soc. Sci. 2016, 21, 12-32. [CrossRef]

15. Bressers, H. From public adminsitration to policy networks: Contextual Interaction analysis. In Rediscovering Public Law and Public Adminsitration in Comparative Policy Analysis: A Tribute to Peter Knoepfel; Narath, S., Varone, F., Eds.; Presses Polytechniques: Lausanne, Switzerland, 2009; pp. 123-142.

16. Bressers, H.; Bressers, N.; Kuks, S.; Larrue, C. The Governance Assessment Tool and its use. In Governance for Drought Resilience; Springer International Publishing: Basel, Switzerland, 2016; pp. 45-65.

17. Casiano Flores, C.A. Context Matters: Water Governance Assessment of the Wastewater Treatment Plant Policy in Central Mexico; University of Twente: Enschede, The Netherlands, 2017.

18. Kuks, S. Water Governance and Institutional Changes. Ph.D. Thesis, University of Twente, Enschede, The Netherlands, 2004.

19. Bressers, H.; Kuks, S. Integrated Governance and Water Basin Management: Conditions for Regime Change towards Sustainbaility; Kluwer Academi Publishes: Dordrecht, The Netherlands; Boston, MA, USA; London, UK, 2004; pp. 1-265.

20. Bevir, M. Governance: A Very Short Introduction; Oxford University Press: Oxford, UK, 2012.

21. Dinica, V.; Bressers, H. RIO 3 World Climate Energy Event. In The Implementation of Renewable Energy Policies: Theoritical Consideration And Experiences from Spain, the Netherlands and the United Kingdom; Imprinta Express Brazil: Rio de Janerio, Brazil, 2003.

22. Bressers, H.; De Boer, C. Complex and Dynamic Implementation Processes; University of Twente: Enschede, Switzerland, 2012.

23. Bressers, H.; Resenbaum, W.A. What does Governance Mean? From conception to Elaboration. In Achieving Sustainable Development: The Challenge of Governance Across Social Scales; Greenwood Publishing Group: London, UK, 2003; pp. 65-88.

24. Gana, J.A.; Hoppe, T. Assessment of the Governance System Regarding Adoption of Energy Efficient Appliances byHouseholds in Nigeria. Energies 2017, 10, 132. [CrossRef]

25. Schot, J.; Geels, F.W. Strategic niche management and sustainable innovation journeys: Theory, findings, research agenda and policy. Technol. Anal. Strateg. Manag. 2008, 20, 537-554. [CrossRef]

26. Caniëls, M.C.; Romijn, H.A. Actor netwroks n strategic niche management:insights from social netwrok theory. Futures 2008, 40, 613-629. [CrossRef]

27. Geels, F.; Kemp, R.E.D. Transitions, Transformations and Reproduction. Dynamics in Socio-Technical Systems. In Flexibility and Stability in the Innovating; Oxford University Press: Oxford, UK, 2005.

28. Rip, A.; Kemp, R. Human Choice and Climate Change. In Technological Change; Battelle Press: Columbus, OH, USA, 1998; Volume 2, pp. 327-399.

29. Hoogma, R.; Kemp, R.; Schot, J.; Truffer, B. Experimenting for Sustainable Transport: The Approach of Strategic Niche Management; EF\&N Spon: London, UK, 2002.

30. Raven, R.P.J.M. Strategic Niche Management for Biomass: A Comparative Study on the Experimental Introduction of Bioenergy Technologies in the Netherlands and Denmark; Technische Universiteit Eindhoven: Eindhoven, The Netherlands, 2005.

31. Schot, J.; Kemp, R.; Truffer, B. Strategic Niche Management as a Tool for Transition to a Sustainable Transport System (SNMT). Available online: http:/ / cordis.europa.eu/documents/documentlibrary/51667501EN6.pdf (accessed on 10 June 2017).

32. Weber, M.; Hoogma, R.; Lane, B.; Schot, J.W. Experimenting with Sustinable Transport Innovations-A Workbook on Stategic Niche Management; Universiteit Twente: Enschede, The Netherlands, 1999. 
33. Mourik, R.; Raven, R. A Practioner's View on Strategic Niche Management; ECN-E-06-039; Eindhoven University of Technology and Energy Innovations and Transitions Department (Policy Studies Unit), Energy Research Center of the Netherlands ECN: Westerduinweg, The Netherlands, 2006.

34. Delhi Development Authority (DDA). NCR MasterPlan, 2021; DDA: Delhi, India, 2015.

35. Jain, M.; Hoppe, T.; Bressers, H. Introducing the Sectoral System Innovation framework (SSIf) for assessment of niche development on Net Zero Energy Buildings in India. In Proceedings of the Annual NIG Work Conference 2014, Delft, The Netherlands, 27-28 November 2014.

36. GBIG. The Green Building Information Gateway. Available online: http://www.gbig.org/places/25731 (accessed on 10 June 2017).

37. Green Rating for Integrated Habitat Assessment. GRIHA New Construction Manual; TERI: New Delhi, India, 2016.

38. Laustsen, J. Energy Efficiency Requirements in Building Codes, Energy Efficiency. Int. Energy Agency 2008, 2, 477-488.

39. National Housing Bank (NHB); Kreditanstalt für Wiederaufbau (KFW). WP IV: General Residential Buildings Sector Update with Focus on EE/Green Buildings; NHB: New Delhi, India, 2014.

40. Muhr, T.; Friese, S. User's Manual for ATLAS.ti 5.0. Available online: www.atlasti.com/manual.html (accessed on 20 September 2015).

41. Government of India. Fatser, Sustainable and More Inclusive Growth-Approach to the Twelfth Five Year Plan; Planning Commission: New Delhi, India, 2011.

42. Kemp, R.; Schot, J. Regime shifts to sustainablilty through processes of niche formation: The approach of strategic niche management. Technol. Anal. Strateg. Manag. 1998, 10, 175-198. [CrossRef]

43. Mdivani, K.; Hoppe, T. Experience with LEDS and NAMA Low Carbon Strategies: The Case of Georgia. Sustainability 2016, 8, 535. [CrossRef]

(C) 2017 by the authors. Licensee MDPI, Basel, Switzerland. This article is an open access article distributed under the terms and conditions of the Creative Commons Attribution (CC BY) license (http:/ / creativecommons.org/licenses/by/4.0/). 